Editorial

\title{
Acute Coronary Syndromes in Women
}

\author{
Ajit S. Mullasari, MD, DNB, DM, FRCP ${ }^{1}$ \\ 1 Director of Cardiology, The Madras Medical Mission, Co-Founder of \\ STEMI-India \\ Ind J Car Dis Wom 2021;6:248-249.
}

Gone are the days when a woman's worry over heart attack centered entirely on its threat to the men in her life. We now know it is not just a man's problem. Every year, acute coronary syndrome (ACS), the single biggest cause of death across the world, claims women and men in nearly equal numbers. Because symptoms of ACS in women often differ from those in men, they tend to be ignored. ${ }^{1}$ Delayed symptom recognition, both by patients and medical professionals, is an important contributor to delay in treatment and subsequent ACS mortality. ${ }^{2}$ Hence, symptoms of ACS should no longer be labeled as "typical" or "atypical" for women and/or men, rather should be addressed as "women specific symptoms" and both patients and physicians should be educated in early recognition of these symptoms. Historically, women with ACS have had worse outcomes compared with men due to misdiagnosis, late presentation, lower rates of thrombolytic therapy, and cardiac catheterization. ${ }^{3}$ With advances in availability and delivery of revascularization therapies, outcomes seem to have improved between genders in most of the western world. ${ }^{3}$ However, this data cannot be generalized, as the recently published subgroup analysis from the landmark Tamil Nadu-STEMI program showed that women in India are twice as likely to die from a heart attack compared to men. ${ }^{4}$ This pattern of risk also continued even among women less than 45 years of age and persisted up to a year after heart attack. Particularly, the incidence of nonobstructive disease and nonatherosclerotic ACS is higher in women and is associated with greater adverse events including recurrent angina, hospitalization, and death. $^{5}$

Diabetes, hypertension, dyslipidemia, obesity, unhealthy diet, and lack of physical exercise are all traditional risk factors for ACS that are on the rise in women. But more interestingly, recent research shows that the nontraditional risk factors such as depression, anxiety, stress at home, and low social support are much higher in women than in men. ${ }^{6}$

And because of this the incidence of ACS in younger women is on the rise and heart attacks occurring in premenopausal women, once a rare occurrence, are more common today. In addition, women with ACS are less likely to receive guidelinerecommended therapies and sex-related differences in presentation, higher prevalence of comorbidities, and uncertainties in the management of unusual causes of ACS that disproportionally affect women may contribute to these disparities.

There is a lack of robust study data on ACS in women. Women continue to be under represented in the majority of clinical trials, resulting in knowledge gaps and uncertainty about the safety and efficacy of many lifesaving therapies. The interesting study done by Dr. Suma Victor and team in the current issue is a step forward in the right direction toward women-specific research in ACS. This study sets the foundation for future studies in developing countries that aim to characterize patient factors that drive the sex gap in mortality and to propose new approaches for tailoring care to the needs of women. More adequately powered, randomized controlled studies are needed to better understand the optimal use of currently available treatments in clinical practice, to optimize management of ACS in women.

Conflict of Interest

None.

\section{References}

1 Dey S, Flather MD, Devlin G, et al; Global Registry of Acute Coronary Events investigators. Sex-related differences in the presentation, treatment and outcomes among patients with acute coronary syndromes: the Global Registry of Acute Coronary Events. Heart 2009;95(01):20-26

2 Johansson I, Strömberg A, Swahn E. Factors related to delay times in patients with suspected acute myocardial infarction. Heart Lung 2004;33(05):291-300

Address for correspondence Ajit S. Mullasari. MD, DNB, DM, FRCP, Director of Cardiology, The Madras Medical Mission, Co-Founder of STEMI-India,

Chennai, Tamil Nadu, India (e-mail: icvddoctors@mmm.org.in).
DOI https://doi.org/ $10.1055 / \mathrm{s}-0042-1742759$. ISSN 2455-7854. (c) 2022. Women in Cardiology and Related Sciences. All rights reserved.

This is an open access article published by Thieme under the terms of the Creative Commons Attribution-NonDerivative-NonCommercial-License, permitting copying and reproduction so long as the original work is given appropriate credit. Contents may not be used for commercial purposes, or adapted, remixed, transformed or built upon. (https://creativecommons.org/ licenses/by-nc-nd/4.0/)

Thieme Medical and Scientific Publishers Pvt. Ltd., A-12, 2nd Floor, Sector 2, Noida-201301 UP, India 
3 Berger JS, Elliott L, Gallup D, et al. Sex differences in mortality following acute coronary syndromes. JAMA 2009;302(08): 874-882

4 Alexander T, Victor SM, Jayakumaran B, Rajan S, Mullasari S A. Sex-related differences in outcomes for patients with ST Elevation Myocardial Infarction (STEMI): a Tamil Nadu-STEMI program subgroup analysis. Heart Lung Circ 2021;30(12):1870-1875
5 Della Rocca DG, Pepine CJ. What causes myocardial infarction in women without obstructive coronary artery disease? Circulation 2011;124(13):1404-1406

6 Bucholz EM, Strait KM, Dreyer RP, et al. Editor's choice-sex differences in young patients with acute myocardial infarction: a VIRGO study analysis. Eur Heart J Acute Cardiovasc Care 2017;6 (07):610-622 